doi:10.4149/neo_2016_519

\title{
Clinical value of high expression level of CD71 in acute myeloid leukemia
}

\author{
B. WUं, N. SHI", L. SUN, L. LIU* \\ Department of Hematology, the First Affiliated Hospital of Zhengzhou University, Zhengzhou, Henan, China \\ *Correspondence: liulinxiang6629@126.com \\ ${ }^{*}$ Contributed equally to this work.
}

Received February 2, 2016 / Accepted June 1, 2016

\begin{abstract}
CD71 (transferrin receptor 1, TfR-1) is a type II membrane glycoprotein and associated closely with tumors. It was recognized as an indication for diagnosing acute erythroid leukemia (AEL). High expression level of CD71 has been identified as a negative prognostic marker for many solid tumors. However, whether CD71 should be identified as an adverse marker in acute myeloid leukemia (AML) remained conflicting. We studied 214 AML patients for analysis of clinical and laboratory data. Taking the CD71 expression level of $60 \%$ as a standard, we divided our patients into two groups. We discovered that AML with high expression level of CD71 was prone to linked with severe anemia $(P=0.004)$, thrombocytopenia $(P<0.001)$ and complex karyotype $(P=0.024)$ and had increasing expression level of CD117 $(P=0.001)$. No statistically significant correlations in age, gender, WBC counting, molecular markers between the two groups. And moreover, high expression level of CD71 did not alter the pattern of survival time.
\end{abstract}

Key words: CD71, acute myeloid leukemia, differentiation, cytogenetics, survival

CD71 is a type II membrane glycoprotein that plays an important role in iron uptake, and its expression is mainly regulated by the iron level in the cell [1]. Most cells have certain expression levels of CD71 in cell membrane; furthermore, CD71 is a wellknown marker of cell proliferation $[2,3]$. Cell with a higher proliferation rate often expresses higher level of CD71.

To cope with the increasing requirement of iron for DNA synthesis, tumor cells usually express higher levels of CD71 [4]. In normal bone marrow, nearly $80 \%$ of CD71 positive cells are erythroid cells. Consequently, CD71 was mainly considered as a typical marker for the diagnosis of AEL [5-8]. High expression level of CD71 has been identified as a negative prognostic marker for many solid tumors $[9,10]$ in addition for non-Hodgkin's lymphoma [11]. However, there was very little information in relationship between CD71 and acute leukemia. The data available from previous studies on whether CD71 was an adverse marker was conflicting [12-16]. And all these studies concentrated on the positive expression level of CD71 and did not associated with current risk statement assessment. In this study, we reviewed $214 \mathrm{AML}$ patients in order to evaluate the potential clinical significance of high expression level (an expression level of $60 \%$ ) of CD71 comprehensively.

\section{Patients and methods}

Patients. 214 patients diagnosed with AML in the Department of Hematology of the First Affiliated Hospital of Zhengzhou University from July 1, 2014 to October 31, 2015 were enrolled into this study. There were 108 males and 106 females, mean age 45 years.

Diagnostic criteria. The bone marrows were routinely assessed by the hematological diagnostic laboratory for analysis of morphology, immunology, cytogenetics and molecular cytogenetics. The diagnoses were made according to the World Health Organization (WHO) 2008 diagnostic criteria.

Reject criteria. Patients diagnosed with acute promyelocytic leukemia (APL) in the same period.

CD71 analysis. Samples were analyzed by flow cytometry using a Backman EPICS XL instrument. Five data parameters were assessed: forward and side scatter (FSC, SSC), FL-1 (FITC), FL-2 (PE) and FL-3 (PE-Cy5). Taking the CD71 expression level of $60 \%$ as a standard, we divided our patients into two groups--CD71-High: the expression level of CD71 $\geq 60 \%$ and CD71-Low: the expression level of CD71<60\%.

Gene detection. The two fusion genes, AML1/ETO and CBF $\beta / M Y H 11$, were detected by the FISH using the OLYM- 


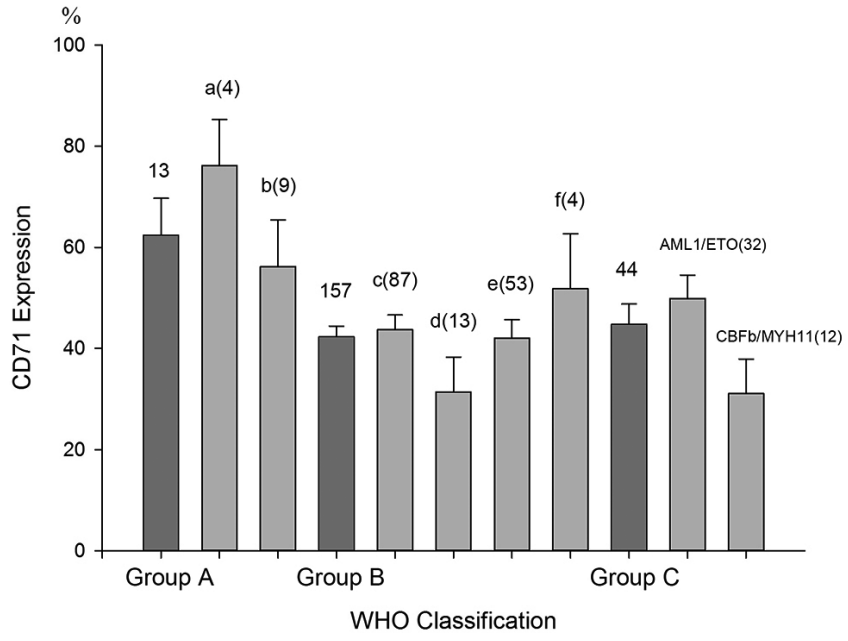

Figure 1. Expression levels of CD71 in different WHO classifications. Group A contained AML with minimal differentiation (a) and AML without differentiation (b). Group B contained AML with maturation (c), Acute myelomonocytic leukemia (d), Acute monoblastic/monocytic leukemia (e), Acute erythriod leukemia (f). Group C contained AML with $t(8 ; 21)$ and $A M L$ with $\operatorname{inv}(16) / t(16 ; 16)$. The numbers in the graph indicated the cases of patients.

PUS analyzer and the imstar software. The gene mutations of NPM1, FLT3-ITD, CEBPA and C-KIT were detected by the Gene Amp PCR System 9700 and the 3130 genetic analyzer.

Therapy strategy. For the patients whose age were less than 60 years old, those patients were given the therapy of "DA" consisted of daunorubicien $45 \mathrm{mg} / \mathrm{m}^{2}$ for 3 days and cytarabine $100 \mathrm{mg} / \mathrm{m}^{2}$ for 7 days. Following induction, patients achieving CR1 were consolidated with "HiDAC" contained cytarabine $2 \mathrm{~g} / \mathrm{m}^{2}$ for 3 days. Patients assessed as better-risk would be consolidated with 3 circles and intermediated-risk with 4 circles. Autologous HSCT or allogeneic HSCT was implemented in the following situations: (a) patients considered at poor-risk status based on cytogenetics and molecular abnormalities and consolidated after 2-3 therapies of "HiDAC", (b) patients failing to achieve CR1 after "DA" and "HiDAC". The BuCy was used as conditioning regimens for both autologous and allogeneic HSCT.

Table 1. Relationships between CD71 expression and clinical factors

\begin{tabular}{lccc}
\hline Clinical Factors $^{\mathrm{a}}$ & $\begin{array}{c}\text { CD71-High } \\
(\mathbf{N}=66)\end{array}$ & $\begin{array}{c}\text { CD71-Low } \\
(\mathbf{N}=\mathbf{1 4 8})\end{array}$ & $\boldsymbol{P}$ \\
\hline Age $\geq 60$ & $14(21.2 \%)$ & $42(28.4 \%)$ & 0.271 \\
Male & $38(57.6 \%)$ & $70(47.9 \%)$ & 0.194 \\
$\mathrm{WBC}>100 \times 10^{9} / \mathrm{L}$ & $15(22.7 \%)$ & $22(14.9 \%)$ & 0.160 \\
$\mathrm{Hb}<60 \mathrm{~g} / \mathrm{L}$ & $21(31.8 \%)$ & $22(14.9 \%)$ & 0.004 \\
$\mathrm{PLT}<20 \times 10^{9} / \mathrm{L}$ & $30(45.5 \%)$ & $26(17.6 \%)$ & $<0.001$ \\
\hline
\end{tabular}

a.Normal: WBC 4-10×109/L, Hb 120-160 g/L, PLT 100-300×10\%/L
In relapsing patients, rescue therapy mainly included 3-drug fludarabine-based regimens. After that, allogeneic HSCT was the treatment of choice in all patients with a potential HLA-matched donor.

For the patients who aged more than 60 years, they were still intensively treated with curative intent, using either the same regimens as younger patients or their reduced versions.

Statistical analysis. Statistical analyses were done with SPSS 21.0 statistical software. Mann-Whitney U-tests were used for the analyses of CD71 expression in different WHO classifications. The Chi-square tests and Fisher's exact tests were used for the qualitative analyses. The Logistic regression was used in the analyses of relationships between CD71 and CD34, HLA-DR and CD117. Survival curves of patients were prepared by the Kaplan-Meier method, and differences between the survival curves were evaluated using log-rank tests. Binary logistic regression and the Cox model (a method of enter was used) were used for the multivariate analysis of associations between CD71 expression level and OS and DFS. A value $P<0.05$ was considered to be significant.

\section{Results}

AMLs with highly CD71 expressed represented adverse biological profiles. The data of age, gender, WBC counting, $\mathrm{Hb}$ counting and PLT counting in the time of diagnosis were taken into our analyses. As Table 1 showed, Percentage of severe anemia ( $31.8 \%$ vs $14.9 \%, P=0.004)$ and thrombocytopenia (45.5\% vs $17.6 \%, P<0.001$ ) in CD71-high AMLs (expression level $\geq 60 \%$ ) were significant higher than those in CD71-low AMLs (expression level $<60 \%$ ). Especially, nearly half of the patients with CD71 highly expressed had a PLT counting less than $20 \times 10^{9} / \mathrm{L}$. There were no significances in age $(\geq 60)$, gender and WBC counting.

AMLs with higher levels of CD71 expression might be linked with poorly differentiated. We divided the WHO classifications into three groups. Group A contained AML

Table 2. Relationships between CD71 expression and WHO classifications

\begin{tabular}{lccc}
\hline Morphology & $\begin{array}{c}\text { CD71-High } \\
(\mathbf{N}=66)\end{array}$ & $\begin{array}{c}\text { CD71-Low } \\
(\mathbf{N}=148)\end{array}$ & $P$ \\
\hline Group A & $8(12.1 \%)$ & $5(3.4 \%)$ & 0.025 \\
AML with minimal differentiation & $3(4.5 \%)$ & $1(0.7 \%)$ & 0.088 \\
AML without differentiation & $5(7.6 \%)$ & $4(2.7 \%)$ & 0.138 \\
Group B & $43(65.2 \%)$ & $114(77.0 \%)$ & 0.070 \\
AML with maturation & $27(40.9 \%)$ & $60(40.5 \%)$ & 0.960 \\
Acute myelomonocytic leukemia & $2(3.0 \%)$ & $11(7.4 \%)$ & 0.353 \\
Acute monoblastic/monocytic leukemia & $12(18.2 \%)$ & $41(27.7 \%)$ & 0.136 \\
Acute erythriod leukemia & $2(3.0 \%)$ & $2(1.4 \%)$ & 0.589 \\
Group C & $15(31.8 \%)$ & $29(14.9 \%)$ & 0.600 \\
AML with t(8;21) & $13(22.7 \%)$ & $19(12.8 \%)$ & 0.194 \\
AML with inv(16)/t(16;16) & $2(3.0 \%)$ & $10(6.8 \%)$ & 0.351 \\
\hline
\end{tabular}



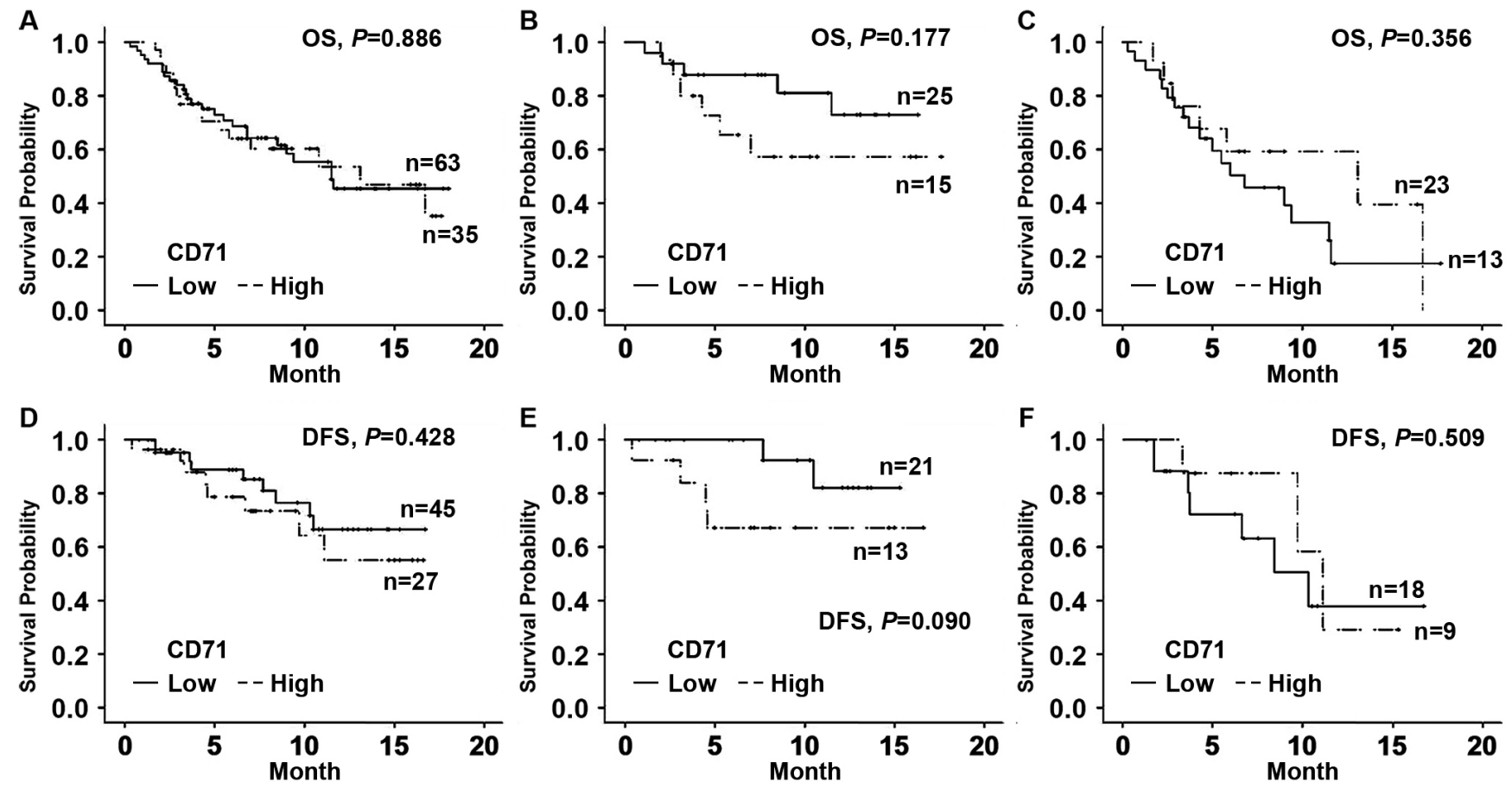

Figure 2. Survival curves of acute myeloid leukemia patients.

(A). OS of the whole samples in CD71-High and CD71-Low. (B). OS of better-risk in CD71-High and CD71-Low. (C). OS of intermediate-risk in CD71High and CD71-Low. (D). DFS of the whole samples in CD71-High and CD71-Low. (E). DFS of better-risk in CD71-High and CD71-Low. (F). DFS of intermediate-risk in CD71-High and CD71-Low. The risk status assessment was according to the NCCN guideline of AML 2015 based on cytogenetics and molecular markers.

with minimal differentiation and AML without differentiation. Group B contained AML with maturation, acute myelomonocytic leukemia, acute monoblastic/monocytic leukemia, acute erythriod leukemia (no acute megakaryocytic leukemia in our study). Group C contained AML with $t(8 ; 21)$ and AML with inv(16)/t(16;16). In this division, AMLs in Group A were poorly differentiated than those in the remained two groups.

As Figure 1 showed (variables were written as mean \pm standard deviation, minimum and maximum, median), Group A had the highest level with an expression level of $62.4 \% \pm 26.2 \%(17.2 \%$ $96.7 \%, 64.6 \%)$. Group B expressed 44.8\% $26.5 \%$ (1.2\%-92.8\%, $42.9 \%)$, which ranked the second. The lowest one was Group C expressing $42.3 \% \pm 26.7 \%$ (0.9\%-98.9\%, 41.1\%). Our results showed that poorly differentiated leukemias often had higher expression levels of CD71 than well differentiated ones $(P=0.011$, Group A vs Group B; $P=0.046$, Group A vs Group C).
In Table 2 listed the proportion of each WHO classification in the CD71-High and CD71-Low groups. This analysis demonstrated that the rate of poorly differentiated AML (Group A) in CD71-High group was significant higher than that in the CD71-Low group $(P=0.025)$. The insignificances of AML with minimal differentiation and AML with differentiation were probably caused by the insufficient data. And for the other classification, we did not find any significance.

We then described the correlation of CD71 with the three classical early antigens-CD34, HLA-DR and CD117 to confirm the relationship of CD71 expression and differentiation. Our results (Table 3) demonstrated that CD71 expression had significant positive correlation with CD117 expression $(\mathrm{OR}=1.024, P=0.001)$. For CD34 and HLA-DR, the correlations were not significant.

Table 3. Relationships between CD71 expression and CD34, HLA-DR, CD117 expression

\begin{tabular}{|c|c|c|c|c|}
\hline Differentiation Antigens & CD71-High $^{\mathrm{a}}$ & CD71-Low ${ }^{\mathrm{a}}$ & $P$ & OR $(95 \% \mathrm{CI})$ \\
\hline CD34 & $48.6 \% \pm 34.4 \%$ & $42.7 \% \pm 35.1 \%$ & 0.360 & $0.994(0.983-1.006)$ \\
\hline HLA-DR & $62.0 \% \pm 34.3 \%$ & $54.1 \% \pm 31.8 \%$ & 0.263 & $1.007(0.995-1.019)$ \\
\hline CD117 & $65.5 \% \pm 24.1 \%$ & $51.6 \% \pm 29.2 \%$ & 0.001 & $1.024(1.009-1.038)$ \\
\hline
\end{tabular}

a. variables were written as mean \pm standard deviation 
Table 4. Relation between CD71 expression and cytogenetics ${ }^{\mathrm{a}, \mathrm{b}}$

\begin{tabular}{lccc}
\hline Cytogenetics & CD71 -High (n=66) & CD71-Low (n=148) & $\boldsymbol{P}$ \\
\hline Better-Risk & $12(18.2 \%)$ & $24(16.2 \%)$ & 0.723 \\
inv(16) & $3(4.5 \%)$ & $10(6.8 \%)$ & 0.758 \\
t $(8 ; 21)$ & $9(13.6 \%)$ & $14(9.5 \%)$ & 0.362 \\
Intermediate-Risk & $41(62.1 \%)$ & $104(70.3 \%)$ & 0.239 \\
normal & $29(43.9 \%)$ & $83(56.1 \%)$ & 0.101 \\
+8 alone & $2(3.0 \%)$ & $7(4.7 \%)$ & 0.724 \\
t(9;11) & $0(0.0 \%)$ & $1(0.7 \%)$ & 1.000 \\
other & $10(15.2 \%)$ & $13(8.8 \%)$ & 0.165 \\
Poor-Risk & $10(15.2 \%)$ & $16(10.8 \%)$ & 0.348 \\
Complex & $11(16.7 \%)$ & $10(6.8 \%)$ & 0.024 \\
$-5 ; 5 q-;-7 ; 7 q-$ & $2(3.0 \%)$ & $9(6.1 \%)$ & 0.509 \\
inv(3) & $0(0.0 \%)$ & $1(0.7 \%)$ & 1.000 \\
t(6;9) & $0(0.0 \%)$ & $2(1.4 \%)$ & 1.000 \\
t(9;22) & $1(1.5 \%)$ & $0(0.0 \%)$ & 0.308 \\
$11 q 23$ & $1(1.5 \%)$ & $2(1.4 \%)$ & 1.000 \\
\hline
\end{tabular}

(a). The data was given in terms of "cases(proportion)".

(b). There was some overlap in this table. For instance, a cytogenetics of " 47 , $\mathrm{xy},+21, \operatorname{del}(9)(\mathrm{q} 23), \operatorname{del}(7)(\mathrm{q} 21)$ [20]" would be counted in rows of "Complex" and "-5;5q-;-7;7q-" but only tallied once in "poor-risk".

AMLs with highly CD71 expressed were more easily associated with complex aberrant cytogenetics. Cytogenetic abnormalities are the most powerful predictor of outcome and are essential in guiding AML treatment decisions. The NCCN had established a risk status for AML based on validated cytogenetics and molecular abnormalities. We tried to find any possible relationship in CD71 expression and aberrant cytogenetics. As Table 4 Showed, percentage of complex karyotype in group of CD71-high was significantly higher than that in CD71-low (16.7\% vs $6.8 \%, P=0.024)$. There were no statistic indications in any other cytogenetics.

Some molecular abnormalities have prognostic implications among the cytogenetically normal group of AML. Point mutation or internal tandem duplication in the FLT3 gene means a prognosis similar to that of AML with adverse risk cytogenetics. Isolated mutation in the NPM1 gene and the CEBPA gene confer a favorable prognosis. A C-KIT mutation in CBF-AML drags down the risk status and confers an intermediate prognosis. As Table 5 showed, mutative rates of NPM1, FLT3-ITD, C-KIT and CEBPA in the two groups were not significant neither calculated in normal karyotype nor calculated in the overall sample. In fact, in our study, the proportions of NPM1, FLT3-ITD and CEBPA increased as CD71 expression increased but the differences were not significant. In addition, isolate NPM1 $(34.8 \%$ vs $21.8 \%$, $P=0.232)$, CEBPA (21.7\% vs $18.2 \%, P=0.757)$ and FLT3-ITD ( $8.7 \%$ vs $3.6 \%, P=0.577)$ mutation was not significant in normal karytpye (variables were given as "CD71 $\geq 60 \%$ vs CD71<60\%, P")

High expression level of CD71 seemed not to impact the survival time neither in OS nor in DFS. A total of 98 cases did the therapy and 82 cases got released. Our outcomes showed that the survival curves of OS $(P=0.909)$ and DFS $(P=0.649)$ of the two groups were quite close (Figure 2-A,D). We classified our patients into three groups according to the risk status, we found that high expression level of CD71 dragged down the OS $(P=0.177)$ and DFS $(P=0.177)$ in the groups of better risk (Figure2-B,E) though there was no significance. And the differences were not significant as well in the intermediate risk group (Figure2-C,F). We did not analysis the impact in the poor risk group because there were merely 12 cases did the therapy. In multivariate analysis, factors as age, gender, WBC counting, risk status assessment and CD71 expression were taken in consideration. As Table 6 demonstrated, age and risk status assessment seemed to strongly connect with overall survival time in AML when gender, WBC counting and CD71 expression level seemed not. In the analysis of DFS, the expression level of CD71 also did not have impacts.

\section{Discussion}

This thesis aimed to evaluate the probably clinical significance of high expression level of CD71 in AML. We tested CD71 expression in 214 patients by flow cytometry. Taking expression level of $60 \%$ as a standard, our result showed that AMLs with high CD71 expressed were easily linking with severe anemia $(\mathrm{Hb}<60 \mathrm{~g} / \mathrm{L}, P=0.004)$ and thrombocytopenia $\left(\mathrm{PLT}<20 \times 10^{9} / \mathrm{L}, P<0.001\right)$. Since CD71 was a well known marker of proliferation, higher expression level of CD71 might mean a higher level of proliferation of leukemic cell. This process might lead to a strong repression to normal hematological generation. Moreover, as PLT counting less than $20 \times 10^{9} / \mathrm{L}$ meant an increasing rate of fatal hemorrhage, AMLs with

Table 5. Relation between CD71 expression and molecular marker

\begin{tabular}{|c|c|c|c|c|c|c|}
\hline \multirow[b]{2}{*}{ Molecular } & \multicolumn{2}{|c|}{ Normal karyotype } & \multirow[b]{2}{*}{$P$} & \multicolumn{2}{|c|}{ Overall sample } & \multirow[b]{2}{*}{$P$} \\
\hline & $\begin{array}{c}\text { CD71-High } \\
(\mathbf{n}=23)\end{array}$ & $\begin{array}{c}\text { CD71-Low } \\
(\mathbf{n}=55)\end{array}$ & & $\begin{array}{c}\text { CD71-High } \\
(\mathrm{n}=41)\end{array}$ & $\begin{array}{c}\text { CD71-Low } \\
(\mathbf{n}=108)\end{array}$ & \\
\hline NPM1 & $13(56.5 \%)$ & $21(38.2 \%)$ & 0.136 & $14(34.1 \%)$ & $23(21.3 \%)$ & 0.105 \\
\hline FLT3-ITD & $7(30.4 \%)$ & $11(20.0 \%)$ & 0.319 & $9(22.0 \%)$ & $14(13.0 \%)$ & 0.175 \\
\hline C-KIT & $0(0.0 \%)$ & $1(1.8 \%)$ & 1.000 & $2(4.9 \%)$ & $6(5.6 \%)$ & 1.000 \\
\hline CEBPA & $5(21.7 \%)$ & $10(18.2 \%)$ & 0.757 & $6(14.6 \%)$ & $15(13.9 \%)$ & 0.907 \\
\hline
\end{tabular}


Table 6. multivariate analysis of CD71 expression in survival time

\begin{tabular}{|c|c|c|c|c|}
\hline Factors & $P_{1}(\mathrm{OS})$ & OR (95\% CI) & $P_{2}(\mathrm{DFS})$ & OR (95\% CI) \\
\hline \multicolumn{5}{|c|}{ CD71 expression } \\
\hline$<60 \%$ & & 1.000 & & 1.000 \\
\hline$\geq 60 \%$ & 0.947 & $1.022(0.532-1.962)$ & 0.498 & $0.690(0.236-2.020)$ \\
\hline \multicolumn{5}{|l|}{ Age } \\
\hline$<60$ years & & 1.000 & & 1.000 \\
\hline$\geq 60$ years & 0.001 & $0.274(0.125-0.602)$ & 0.253 & $0.396(0.081-1.938)$ \\
\hline \multicolumn{5}{|l|}{ Gender } \\
\hline Female & & 1.000 & & 1.000 \\
\hline Male & 0.271 & $0.697(0.366-1.327)$ & 0.891 & $1.080(0.360-3.233)$ \\
\hline \multicolumn{5}{|l|}{ WBC counting } \\
\hline$<100 \times 10^{9} / \mathrm{L}$ & & 1.000 & & 1.000 \\
\hline$\geq 100 \times 10^{9} / \mathrm{L}$ & 0.798 & $0.900(0.404-2.006)$ & 0.312 & $2.225(0.473-10.472)$ \\
\hline Risk status ${ }^{\mathrm{a}}$ & 0.015 & & 0.075 & \\
\hline better & & 1.000 & & 1.000 \\
\hline intermediate & 0.004 & $2.888(1.402-5.949)$ & 0.032 & $3.155(1.104-9.015)$ \\
\hline poor & 0.246 & $1.818(0.662-4.995)$ & 0.961 & $0.947(0.107-8.399)$ \\
\hline
\end{tabular}

a. The risk status assessment was according to the NCCN guideline of AML 2015 based on cytogenetics and molecular markers.

highly CD71 expressed were exposed to a more dangerous state in the first visit to hospital.

In morphology, our results showed that poorly differentiated AMLs often had higher expression levels of CD71 than well differentiated ones. On the other hand, we also found that the proportion of poorly differentiated AMLs in CD71 highly expressed group was higher than that in the CD71 lowly expressed group. This meant that high expression level of CD71 seemed to be linked with poor differentiation. The result was partially coincident with the previous reporting [17]. The results of FCM demonstrated that CD117 expression was positively correlated with CD71 expression. One thing is for certain, as cellular differentiation is a continuous process, cells in the same stage defined by human can be actually diversely differentiated. In our knowledge, CD117, a receptor tyrosine kinase protein encoded by KIT gene, is mostly expressed on cells that are not mature in morphology such as hematopoietic stem cells [18]. The expression intensity declines as the cells differentiate in the normal bone marrow. Signalling through CD117 plays a role in cell survival, proliferation and differentiation. In this context, our outcomes might show that leukemic cells with CD71 highly expressed were more primitive than the lowly expressed ones.

The cellular labile iron pool (LIP) is a pool of chelatable and redox-active iron, which is transitory and serves as a crossroad of cell iron metabolism [19]. Higher CD71 expression meant an increasing absorption of iron and resulted in the iron overload and the increasing level of LIP. The labile nature of LIP was revealed by its capacity to promote formation of reactive oxygen species (ROS). The ROS was then to impair the DNA [20] and to influence the cell cycle of hematopoietic stem and progenitor cells by MAPK pathway [21]. In erythroid, the ROS was mainly to blockade the differentiation of progenitor cells and to destruct the structure of red blood cells [22]. As a result, AML with highly CD71 expressed showed an enhanced pattern of poorly differentiated and severe anemia.

Proto-oncogene and tumor suppressor gene play a key role in the occurrence and development of tumors. Such translocation, insertion and deletion as chromosome abnormalities are closely linked with gene conversions. One of the activation methods of proto-oncogene is DNA rearrangement such as Burkitt lymphoma or Class II genes AML1/ETO and $\mathrm{CBFb} / \mathrm{MYH} 11$. Low tumor suppressor gene dosage caused by chromosome deletions or gene mutations also contributes to the tumor generation [23]. Gene transformation result from chromosome abnormality is then lead to the abnormality of survival pathway and eventually result in tumor.

AML is commonly accompanied with chromosome abnormalities. Our results indicated that AMLs with high level of CD71 expression were more easily associated with complex karyotype $(P=0.024)$. Since surface CD71 expression has been proven to be a downstream marker of Notch mediated PDK1 activation $[24,25]$ and further proposed as a downstream marker of mTOR activity [26], it seems that activity of survival pathway such as PI3K/PDK1/Akt/mTOR is linked with CD71 expression. Kenneth showed that CD71 interacts with the IKK complex and is involved in IKK-NF- $\mathrm{KB}$ signaling [27]. Enhanced expression of TfR 1 had been showed to contribute to oncogenic signalling by sphingosine kinase 1 [28]. In this context, we supposed that contrasted with uncomplex karyotype, complex karyotype had more frame shift mutations like translocation, insertion and deletion in chromosomes, increasing the incidence rates of the following events: activating or amplifying a proto-oncogene, inactivating a tumor 
suppressor gene or reducing its dosage. The comprehensive result was that the abnormality of the signal system controlling cell proliferation and differentiation became more obvious, which then led to the stronger malignant clone ability and earlier differentiation blockade of leukemic cells. Therefore, the expression level of CD71 increased.

Whether CD71 expression should affect survival remained controversial. Our results showed that the survival curves of CD71-high and CD71-low were quite close. And the multivariate analysis as well suggest that high expression level of CD71 did not change the pattern of survival. This meant that the high expression level of CD71 might not influence survival though it linked with poor clinical and laboratory profiles. Our results seemed to support the precious negative studies $[12,14]$. Interestingly, we found that highly expressed level of CD71 dragged down the AML with better risk assessment. However, because of the data insufficient and shortly observing time, this difference was also not to be significant. Whether it was a prognostic marker in better risk group remained further studying.

In conclusion, CD71 was a marker for proliferation. AML expressed high level of CD71 might have an adverse clinical and laboratory profile. It was easily associated with severe anemia, thrombocytopenia, poor differentiation and complex cytogenetics. However, high expression level of CD71 might not impact survival time neither in OS nor in DFS.

Acknowledgements: We thank Ping Tang, Li Chen, Hui sun, Yanfang Liu, Zhongxing Jiang, Dingming Wan, Shaoqian Chen, Xiaoli Meng, Fang Wang, Shengmei Chen, Jie Ma, Xinsheng Xie, Rong Guo, Yuandong Cheng, Yingmei Li, Chong Wang for generous supporting.

\section{References}

[1] HERBISON CE, THORSTENSEN K, CHUA AC, GRAHAM $\mathrm{RM}$, LEEDMAN $\mathrm{P}$ et al. The role of transferrin receptor 1 and 2 in transferrin-bound iron uptake in human hepatoma cells. Am J Physiol Cell Physiol 2009; 297: C1567-1575. http:// dx.doi.org/10.1152/ajpcell.00649.2008

[2] O'DONNELL KA, YU D, ZELLER KI, KIM JW, RACKE F et al. Activation of transferrin receptor 1 by c-Myc enhances cellular proliferation and tumorigenesis. Mol Cell Biol 2006; 26: 2373-2386. http://dx.doi.org/10.1128/MCB.26.6.23732386.2006

[3] SCHAAR DG, MEDINA DJ, MOORE DF, STRAIR RK, TING Y. miR-320 targets transferrin receptor 1 (CD71) and inhibits cell proliferation. Exp Hematol 2009; 37: 245-255. http:// dx.doi.org/10.1016/i.exphem.2008.10.002

[4] GOMME PT, MCCANN KB, BERTOLINI J. Transferrin: structure, function and potential therapeutic actions. Drug Discov Today 2005; 10: 267-273. http://dx.doi.org/10.1016/ S1359-6446(04)03333-1

[5] DONG HY, WILKES S, YANG H. CD71 is selectively and ubiquitously expressed at high levels in erythroid precursors of all maturation stages: a comparative immuno- chemical study with glycophorin A and hemoglobin A. Am J Surg Pathol 2011; 35: 723-732. http://dx.doi.org/10.1097/ PAS.0b013e31821247a8

[6] MIHOVA D, ZHANG L. Acute erythoid leukemia: a review. N Am J Med Sci 2012; 5: 110-112. http://dx.doi.org/10.7156/ v5i2p110

[7] SHARMA A, BUXI G, WALIA R, YADAV RB, SHARMA S. Childhood acute erythroleukemia diagnosis by flow cytometry. Indian J Pathol Microbiol 2011; 54: 173-175. http:// dx.doi.org/10.4103/0377-4929.77395

[8] WOOD BL. Myeloid malignancies: myelodysplastic syndromes, myeloproliferative disorders, and acute myeloid leukemia. Clin Lab Med 2007; 27: 551-575, vii. http://dx.doi. org/10.1016/i.cll.2007.05.006

[9] CHAN KT, CHOI MY, LAI KK, TAN W, TUNG LN et al. Overexpression of transferrin receptor CD71 and its tumorigenic properties in esophageal squamous cell carcinoma. Oncol Rep 2014; 31: 1296-1304.

[10] HABASHY HO, POWE DG, STAKA CM, RAKHA EA, BALL $G$ et al. Transferrin receptor (CD71) is a marker of poor prognosis in breast cancer and can predict response to tamoxifen. Breast Cancer Res Treat 2010; 119: 283-293. http://dx.doi. org/10.1007/s10549-009-0345-x

[11] DANIELS TR, DELGADO T, RODRIGUEZ JA, HELGUERA G, PENICHET ML. The transferrin receptor part I: Biology and targeting with cytotoxic antibodies for the treatment of cancer. Clin Immunol 2006; 121: 144-158. http://dx.doi. org/10.1016/j.clim.2006.06.010

[12] BRADSTOCK K, MATTHEWS J, BENSON E, PAGE F, BISHOP J. Prognostic value of immunophenotyping in acute myeloid leukemia. Blood 1994; 84: 1220-1225.

[13] GLASOVA M, KONIKOVA E, STASAKOVA J, BABUSIKOVA O. The relationship of HLA-DR, CD38 and CD71 markers to activation, proliferation and differentiation of some human leukemia and lymphoma cells. Neoplasma 1998; 45: 88-95.

[14] KOEHLER M, BEHM F, HANCOCK M, PUI CH. Expression of activation antigens CD38 and CD71 is not clinically important in childhood acute lymphoblastic leukemia. Leukemia 1993; 7: 41-45.

[15] KOLLIA P, STAVROYIANNI N, STAMATOPOULOS K, ZOI K, VINIOU $\mathrm{N}$ et al. Molecular analysis of transferrin receptor mRNA expression in acute myeloid leukaemia. Br J Haematol 2001; 115: 19-24. http://dx.doi.org/10.1046/j.13652141.2001.03065.x

[16] PLOSZYNSKA A, RUCKEMANN-DZIURDZINSKA K, JOZWIK A, MIKOSIK A, LISOWSKA K et al. Cytometric evaluation of transferrin receptor 1 (CD71) in childhood acute lymphoblastic leukemia. Folia Histochem Cytobiol 2012; 50: 304-311. http://dx.doi.org/10.5603/FHC.2012.0040

[17] LIU Q, WANG M, HU Y, XING H, CHEN X et al. Significance of CD71 expression by flow cytometry in diagnosis of acute leukemia. Leuk Lymphoma 2014; 55: 892-898. http://dx.doi. org/10.3109/10428194.2013.819100

[18] AUEWARAKUL CU, LAUHAKIRTI D, PROMSUWICHA O, MUNKHETVIT C. C-kit receptor tyrosine kinase (CD117) expression and its positive predictive value for 
the diagnosis of Thai adult acute myeloid leukemia. Ann Hematol 2006; 85: 108-112. http://dx.doi.org/10.1007/ $\underline{\text { s00277-005-0039-3 }}$

[19] KAKHLON O, CABANTCHIK ZI. The labile iron pool: characterization, measurement, and participation in cellular processes. Free Radic Biol Med 2002; 33: 1037-1046. http:// dx.doi.org/10.1016/S0891-5849(02)01006-7

[20] GHAFFARI S. Oxidative stress in the regulation of normal and neoplastic hematopoiesis. Antioxid Redox Signal 2008; 10: 1923-1940. http://dx.doi.org/10.1089/ars.2008.2142

[21] ITO K, HIRAO A, ARAI F, TAKUBO K, MATSUOKA S et al. Reactive oxygen species act through p38 MAPK to limit the lifespan of hematopoietic stem cells. Nat Med 2006; 12: 446-451. http://dx.doi.org/10.1038/nm1388

[22] JOHNSON RM, GOYETTE G, JR., RAVINDRANATH Y, HO YS. Hemoglobin autoxidation and regulation of endogenous $\mathrm{H} 2 \mathrm{O} 2$ levels in erythrocytes. Free Radic Biol Med 2005; 39: 1407-1417. http://dx.doi.org/10.1016/j. freeradbiomed.2005.07.002

[23] BERGER AH, PANDOLFI PP. Haplo-insufficiency: a driving force in cancer. J Pathol 2011; 223: 137-146.
[24] ANDROUTSELLIS-THEOTOKIS A, LEKER RR, SOLDNER F, HOEPPNER DJ, RAVIN R et al. Notch signalling regulates stem cell numbers in vitro and in vivo. Nature 2006; 442: 823-826. http://dx.doi.org/10.1038/nature04940

[25] KELLY AP, FINLAY DK, HINTON HJ, CLARKE RG, FIORINI E et al. Notch-induced T cell development requires phosphoinositide-dependent kinase 1. Embo J 2007; 26: 3441-3450. http://dx.doi.org/10.1038/sj.emboj.7601761

[26] ZHENG Y, COLLINS SL, LUTZ MA, ALLEN AN, KOLE TP et al. A role for mammalian target of rapamycin in regulating $\mathrm{T}$ cell activation versus anergy. J Immunol 2007; 178: 2163-2170. http://dx.doi.org/10.4049/jimmunol.178.4.2163

[27] KENNETH NS, MUDIE S, NARON S, ROCHA S. TfR1 interacts with the IKK complex and is involved in IKK-NFkappaB signalling. Biochem J 2013; 449: 275-284. http:// dx.doi.org/10.1042/BJ20120625

[28] PHAM DH, POWELL JA, GLIDDON BL, MORETTI PA, TSYKIN A et al. Enhanced expression of transferrin receptor 1 contributes to oncogenic signalling by sphingosine kinase 1. Oncogene 2014; 33: 5559-5568. http://dx.doi.org/10.1038/ onc. 2013.502 